\title{
Embates entre paradigmas de políticas para a educação em espaços rurais no Brasil contemporâneo
}

\section{Tássia Gabriele Balbi de Figueiredo e Cordeiro}

C. E. Barão do Rio Branco/SEEDUC-RJ. Brasil.

Email: tassia.cordeiro@gmail.com

\section{Marcia Soares de Alvarenga}

Universidade do Estado do Rio de Janeiro, Rio de Janeiro, Brasil.

Email: msalvarenga.uerj@uol.com.br

Resumo: No presente artigo, discutimos os embates entre perspectivas de políticas para a educação em espaços não-urbanos que vem se configurando no Brasil contemporâneo. Ancoradas nos referenciais teórico-conceituais que envolvem tais embates, adotamos como metodologia o levantamento de dados oficiais sobre escolas rurais no estado do Rio de Janeiro e analisamos que a apropriação discursiva sobre as recentes políticas para a educação de sujeitos em contextos não-urbanos repercute na implementação de políticas públicas que intensificam o processo de agrupamento de escolas fora do território rural, processo este denominado de nucleação. Assim, interrogamos sobre possíveis contradições entre discursos e práticas governamentais de políticas para as escolas rurais. Concluímos que estas contradições expressam disputas na determinação de sentidos sobre e para a educação de crianças, jovens e adultos, cujos paradigmas se confrontam quando materializados nas ações governamentais de implementação de políticas públicas para este setor social.

Palavras-chave: Educação em espaços não-urbanos - Educação do Campo - Políticas Públicas - Nucleação escolar

\section{Los enfrentamientos entre paradigmas de política para la educación en los espacios rurales del Brasil contemporáneo}

Resumen: En este artículo se analizan los enfrentamientos entre las perspectivas sobre las políticas de educación en las zonas no urbanas que ha vendo configurándose en el Brasil contemporáneo. Basado en los marcos teóricos y conceptuales que implican este tipo de conflictos, hemos adoptado como metodología el levantamiento de los datos oficiales sobre las escuelas rurales en el estado de Río de Janeiro y analizamos que la apropiación discursiva sobre las recientes políticas para la educación de los individuos en contextos no urbanos afecta en la implementación de políticas públicas que intensifican el proceso de agrupación de las escuelas fuera de las áreas rurales, proceso llamado de nucleación. Así, nos preguntamos sobre las posibles contradicciones entre los discursos y las prácticas de las políticas gubernamentales para las escuelas rurales. Llegamos a la conclusión de que estas contradicciones expresan las disputas acerca de la determinación de sentidos sobre y para la educación de niños, jóvenes y adultos, cuyos paradigmas 
se enfrentan cuando se materializan en las acciones del gobierno para implementar políticas públicas para este sector social.

Palabras clave: Educación en las zonas no urbanas, Educación Rural, Políticas Públicas, Nucleación escolar

\title{
Clashes between paradigms on policies for education in rural areas in contemporary Brazil
}

\begin{abstract}
In this article, we discuss the clashes between policies for education in non-urban areas that has been setting in contemporary Brazil. Anchored in the theoretical and conceptual frameworks that involve such conflicts, we adopted the methodology of surveying official data on rural schools in the state of Rio de Janeiro and analyze that discursive appropriation on recent policies for the education of individuals in non-urban contexts affects the implementation of public policies that enhance the process of grouping schools outside rural areas, process that is called nucleation. Thus we question about possible contradictions between discourses and practices of government policies for rural schools. We conclude that these contradictions express disputes about the determination of senses about and for the education of children, youth and adults, whose paradigms confront when government actions to implement public policies for this social sector materialize.

Keywords: Education in non-urban areas, Rural Education, Public Policy, School Nucleation.
\end{abstract}

\section{Introdução ${ }^{1}$}

A leitura compreensiva sobre as condições de escolarização dos povos do campo no Brasil tem, historicamente, se efetivado através de políticas erigidas por dois processos latentes. Por um lado, pela via da precariedade infraestrutural e pedagógica existente nas escolas rurais quando comparadas às escolas urbanas, cujas condições, também de precariedade, materializam historicamente as desigualdades educacionais e múltiplas formas de exclusão às quais estão submetidos os filhos de trabalhadores do campo e das periferias urbanas. Particularmente em relação à educação em espaços rurais, vemos a produção de silenciamentos de vozes dos sujeitos que nela se inscrevem. Silenciamentos estes marcados por um modelo econômico que, desde os anos de 1940, atribui aos povos do campo a responsabilidade pelo atraso econômico do país e um obstáculo à sua inserção no círculo dos países desenvolvidos². Por outro lado, evidencia-se o que consideramos uma urbanocentralidade (MEC/SE$\left.\mathrm{CAD}^{3}, 2007\right)$ presente nos currículos, na formação dos profissionais de educação e nos materiais didáticos e de apoio aos professores do campo, o que faz da escola rural uma estranha à própria realidade territorial que a cerca.

Apesar do tratamento periférico dado às escolas rurais, Pinto (2006) ao analisar o censo escolar em 2002, discute que 50\% das escolas do país 
ainda estavam localizadas em áreas rurais, atendendo a 15\% dos alunos matriculados, o que nos faz observar que grande parte das escolas brasileiras seria de pequeno porte e estaria localizada no espaço rural, atendendo a um pequeno número de alunos, o que as tornam extremamente significativas no que tange ao acesso das populações do campo à escolarização. Entretanto, os dados atuais são indicativos de um processo de desestruturação da rede escolar no Brasil rural, visto que de acordo com o Inep (MEC/INEP 2011) em 2011 o total de escolas rurais caiu para 39\%, uma retração de 11\% em menos de uma década.

Neste artigo, analisamos as políticas públicas educacionais destinadas às populações e às escolas do campo do Brasil, tendo como questão problematizadora a política de nucleação posta em prática de maneira mais acentuada nos últimos anos pelo Estado brasileiro, no que se refere à educação em contextos não-urbanos.

A nucleação, entendida aqui em várias dimensões como a transferências de alunos de áreas rurais para escolas longe de suas comunidades, tanto pela desativação da escola como um todo quanto pela desativação de uma etapa do ensino em particular, em tese, afastaria os alunos que vivem no e do meio rural de suas realidades, indo ao encontro do paradigma da educação rural, já que age no deslocamento dos alunos em relação as suas comunidades e, por isso, não estaria de acordo com os princípios norteadores da Educação do Campo.

Observamos o crescente processo de nucleação escolar como principal ação dos governos locais que vem provocando muitos conflitos e tensões entre movimentos sociais populares, comunidades rurais e secretarias de educação, o que nos faz questionar os impactos produzidos nos contextos em que esta política é implantada.

A despeito da disposição de diálogos entre Estado e movimentos sociais, contraditoriamente verifica-se a predominância de uma educação ainda deslocada da realidade rural, sem políticas públicas específicas, e que mais drasticamente vem resultando em política de nucleação escolar, impactando no fechamento de escolas rurais, o que não corresponde às demandas dos movimentos sociais do campo.

Para melhor compreensão das questões por nós desenvolvidas, na primeira parte do artigo abordamos os paradigmas da educação rural e da educação do campo, em diálogo com os autores dedicados às análises que envolvem os embates entre estes paradigmas. Na segunda parte do texto, apresentamos e discutimos dados levantados em fontes oficiais que materializam as ações governamentais que têm resultado na nucleação das escolas rurais, com ênfase em dados específicos do estado do Rio de Janeiro, e por último apresentamos nossas considerações sobre os efeitos produzidos nas disputas envolvidas, os quais precisam continuar sendo analisados no âmbito dos governos, das universidades e dos movimentos sociais. 


\section{Embates entre paradigmas para a educação dos sujeitos dos espaços rurais}

Iniciamos esta primeira parte do artigo abordando sobre alguns dos principais desafios que envolvem a educação escolar dos sujeitos que vivem em espaços rurais. Nesse sentido, abordamos o paradigma da educação rural, pois, como apontam estudos recentes, a educação oferecida nas escolas rurais brasileiras vive em situação de precariedade material e pedagógica.

Considerando as condições, físicas e pedagógicas, da oferta do direito à educação da população do campo, Pinto descreve o seguinte quadro:

Quanto aos recursos disponíveis na escola, ainda para aquelas que oferecem Ensino Fundamental, 21\% não possuem energia elétrica, apenas 5,2\% dispõem de biblioteca e menos de $1 \%$ oferece laboratório de ciências, de informática e acesso à internet. Estes dados indicam a necessidade do estabelecimento de políticas globais para o setor que não negligenciem a especificidade do campo em relação à cidade. (Pinto et al, 2006: 31).

Acerca da educação no campo, alguns dados referentes ao ano de 2007 clarificam a precariedade dessa educação quando comparada àquela ofertada nos espaços urbanos. Estes dados expressam que 23,3\% da população rural é analfabeta contra 7,6\% da população urbana; o número médio de anos de estudo no meio rural é de 4,5 anos e no meio urbano de 7,8 anos; a taxa de escolarização da população de 0 a 3 anos, equivalente à parte da educação infantil, é de 6,4\% no meio rural e de $19,6 \%$ no meio urbano; e a distorção idade-série nos anos iniciais do ensino fundamental é de $38,9 \%$ e nos finais de $51 \%$ no meio rural e respectivamente de $18,4 \%$ e de 31,9\% no meio urbano. (Oliveira, Molina, Montenegro, 2011).

Os dados, também, apontam o quanto a educação oferecida nas escolas no Brasil rural constitui-se como uma violência ao direito à escolarização dos povos do campo. Os estudos de Pinto e de Oliveira, Molina e Montenegro indicam a materialização de uma dupla modalidade de exclusão escolar, uma precariedade dentro da precariedade, ou seja, visto que as escolas urbanas que também recebem crianças, jovens e adultos de contextos rurais, ainda estão longe de um padrão de qualidade, tanto em relação à infraestrutura quanto em relação às questões pedagógicas.

A rigor, os objetivos da educação da classe trabalhadora e dos trabalhadores rurais em particular são pautados em interesses subordinados ao capital. Assim, a educação rural no Brasil atendeu às demandas urbano-industriais a partir da reprodução dos interesses hegemônicos nos espaços rurais, o que nos faz considerar que a educação rural está pautada em uma urbanocentralidade, pois 
A escola rural não é tanto lembrada quando a agricultura ou pecuária estão em crise, mas quando a cidade e sua economia entram em crise [...] a educação rural não é defendida como fim em si mesma, mas como instrumento para outros fins sociais e políticos, como, por exemplo, [...] fixar o homem no campo, evitar o congestionamento e a violência das cidades, ampliar as bases políticas, etc. (Arroyo, 1982: 2).

Nessa mesma perspectiva, Mendonça (2012) nos oferece um inventário dedicado ao paradigma da educação rural no Brasil, especialmente na primeira metade do século XX. Para esta autora, a educação rural não pode prescindir de uma abordagem histórica sobre as relações entre grupos agrários dominantes e o Estado em que estas relações tangenciaram as políticas no ensino rural primário e médio, emergindo de uma imediata conjuntura pós-abolição da escravidão em fins do século XIX.

Mendonça argumenta que nas abordagens historiográficas sobre a educação rural prevalece uma perspectiva instrumental respaldada numa concepção que visa atingir fins sócio-políticos, uma vez que firma a identidade do trabalhador rural com inúmeras carências materiais, culturais, sociais, intelectuais. Em consequência desta perspectiva, segundo a autora,

ratifica-se toda uma construção e uma percepção da escola rural como instituição “especial”, naturalizada e ignorada em seu caráter de construção histórica, logo, fruto de inúmeros embates e disputas. A visibilidade destes últimos exige, justamente, que se desconstrua o que tem sido frequentemente escamoteado e encoberto na história recente do Brasil, sob fórmulas culturalistas as mais atraentes e supostamente inovadoras: os problemas estruturais que perpassam a relação cidade-campo. Subestimar a conflitualidade inerente à própria dinâmica de funcionamento do Estado na configuração de suas políticas - inclusive as educacionais - bem pouco contribui para fazer avançar o conhecimento histórico sobre a problemática. (Mendonça, 2012:273).

Os apontamentos de Mendonça ratificam que as políticas para a educação do campo não podem abdicar das análises sobre a relação cidadecampo, pois é parte da dialética pela qual se estruturou o Estado brasileiro. Com efeito, as críticas ao parâmetro urbanocêntrico têm sido explicitadas em recentes políticas públicas para a educação do campo. De acordo com a SECAD (2007), o parâmetro dominante, urbanocêntrico, está fundado em

uma visão de educação na qual o modelo didático-pedagógico utilizado nas escolas das cidades é transferido para as escolas localizadas nas zonas classificadas como rurais, sem que sejam consideradas as reais necessidades das populações identificadas com o campo. (SECAD, 2007: 13)

No parecer do Conselho Nacional de Educação para as Diretrizes Operacionais para a Educação Básica nas Escolas do Campo também é 
levantada esta questão:

A visão urbano-centrada privilegia o pólo urbano do continuun, mediante um processo de homogeneização espacial e social que subordina o pólo rural [...] Em resumo há, no plano das relações, uma dominação do urbano sobre o rural que exclui o trabalhador do campo da totalidade definida pela representação urbana da realidade. (Parecer n ${ }^{\circ}$ 36/2001).

O modelo explicativo de subordinação do rural ao urbano merece ser complexificado a medida que, como analisa Martins (1995:16), o campesinato no Brasil é constituído com a expansão capitalista como produto das contradições desta expansão, tanto no campo quanto na cidade. As contradições geradas no processo de desenvolvimento capitalista são alargadas desde os centros urbanos industrializados até os territórios rurais onde a população camponesa é expulsa pelas formas tecnificadas da agricultura e da pecuária, pelo fenômeno da desertificação e pelas adversidades das relações sociais de produção no campo: a exploração do latifundiário, a ausência ou insuficientes políticas de reforma agrária que impedem a permanência e as atividades dos trabalhadores rurais sem terra. Assim, a marca da concentração fundiária sob a égide do capitalismo não pode ser negligenciada quando abordamos o problema da educação em espaços rurais, pois a opção do Estado pelo monopólio privado da terra estruturou políticas públicas para a educação rural.

A perspectiva da educação do campo deve ser lida na relação campo-cidade, mas não interpretada de forma linear sem dimensionar a conflitualidade que nela está presente. Como explicita Caldart (2009: 47)

as lutas e as práticas originárias da Educação do campo nunca defenderam ou se colocaram na perspectiva de fortalecer a contradição inventada pelo capitalismo entre campo e cidade. A questão é de reconhecer a especificidade dos processos produtivos e formadores do ser humano que acontecem no campo, compreender como historicamente essa relação foi formatada, exatamente para que se explicitem os termos sociais necessários à superação desta contradição.

Ao negar os saberes próprios dos povos do campo a escola da sociedade capitalista, centrada no modelo urbano privilegiou formas de ver o mundo epistemologicamente hierarquizadas, deflagrando uma invasão cultural $^{4}$ (Freire, 2005) que fez da escola rural uma estranha à realidade campesina. Lopes (apud Leite, 2002: 84) reflete sobre as consequências da urbanocentralidade da educação no Brasil, na qual o espaço e a dinâmica urbana são vistos como superiores. Para o autor,

a escola, no lugar de proporciona-lhe um campo de reflexão sobre sua vida de camponês, acaba impondo-lhe um modelo urbano, que o domina, transmitindo-lhe um saber reforçador de uma estrutura de 
desigualdade e de divisão entre homens cultos (da cidade) e homens incultos (roceiros). (Leite, 2002:84).

Este tratamento desigual destinado à educação do meio rural é evidenciado pela legislação brasileira, já que somente na Constituição de 1934 a educação é considerada dever do Estado e é assegurado seu financiamento público. Até então, a educação em espaços rurais sequer foi citada em constituições, mesmo a população rural sendo majoritária, fato que só começa a se desconfigurar no momento de industrialização e integração brasileira, principalmente a partir da década de 1960 . Dessa forma, a educação dos povos do campo foi deixada nas mãos dos interesses privados da oligarquia rural e dos grupos urbano-industriais dominantes, sendo tratada tanto pelo público quanto pelo privado como política assistencialista.

É importante que tenhamos clareza da dimensão e relevância do descaso a qual foi submetida a educação em geral e a educação rural especificamente, já que até 1934 a população brasileira, enfatizamos em sua maioria rural, não tinha sequer direito à educação. Ao verificarmos as constituições brasileiras e a Lei de Diretrizes e Bases da Educação de 1961 vimos que a educação rural quando citada teve, na maior parte dos textos, um tratamento periférico e inadequado. Esta afirmativa é corroborada por considerarmos que somente na Constituição de 1988 a educação para o meio rural passou a ter um tratamento específico, de acordo com seus próprios fins, desvinculado da educação urbana. Segundo a Secad (2007:15), Antes disso, a educação para essas populações foi mencionada apenas para propor uma educação instrumental, assistencialista ou de ordenamento social.

Desse modo, historicamente foi sendo constituído um paradigma educacional alheio aos interesses da população rural, tendo como principais pressupostos a subordinação ao capital, a urbanocentralidade e a precariedade. Entretanto, este paradigma impregnado e naturalizado em nosso país passa a ser questionado pelos povos do campo, principalmente àqueles ligados aos movimentos sociais populares rurais que, ao tomarem consciência do processo de inferiorização e subalternização existente na escola, decidiram se rebelar diante do descaso existente, lutando pelo reconhecimento de seus direitos enquanto cidadãos e sujeitos históricos, almejando assim uma educação que ao invés de servir à desvalorização do campo e de seus povos servisse a sua valorização. Em uma luta que reconhece a educação a partir da dimensão do direito.

Por sua vez, o processo de conscientização dos movimentos sociais do campo por uma Educação do Campo pode ser delineado a partir de dois pontos: o primeiro diz respeito à luta contra a negação do direito à escola nas próprias comunidades rurais, pelos povos do campo em geral e, principalmente, pelos integrantes do Movimento dos Trabalhadores Rurais Sem Terra (MST) nos assentamentos e acampamentos em particular, sem esquecer da luta indígena e quilombola; o segundo refere-se à rebelião diante do modelo de educação ofertado nas escolas rurais existentes, sendo estas estranhas às especificidades campesinas e à realidade de luta por terra. 
A partir desta conscientização, a educação comprometida com a manutenção das desigualdades socioeconômicas no campo brasileiro e com a visão da educação como instrumento de reprodução e “domesticação” da população rural, que até então era a educação ofertada aos povos rurais, ficou conhecida como paradigma da educação rural. Já a educação reivindicada e proposta pelos movimentos sociais populares rurais, comprometida com a valorização do campo, de seus povos e com a luta pela reforma agrária, não só sediada no campo, mas igualmente comprometida com este, germinada na rebelião contra a educação rural, foi designada de educação do campo. Conforme esclarece Caldart (2005, idem: 19):

A Educação do Campo se constitui a partir de uma contradição que é a própria contradição de classe no campo: existe uma incompatibilidade de origem entre a agricultura capitalista e a Educação do Campo, exatamente porque a primeira sobrevive da exclusão e morte dos camponeses, que são os sujeitos principais da segunda. Em nosso debate isso tem sido referido como a principal oposição com a educação rural ou para o meio rural, que historicamente tem sido o nome dado às iniciativas do Estado de pensar a educação da população trabalhadora do campo, de modo a escamotear esta contradição e fazê-la de objeto e instrumento executor de políticas e modelos de agricultura pensados em outros lugares, e para atender a outros interesses que não os seus como grupo social, classe e pessoas.

Tomando como referência os estudos de Caldart, a Educação do Campo é um conceito novo e contemporâneo que necessita ser compreendido à luz de sua materialidade de origem: a partir da tríade campo - políticas públicas - educação. Com efeito, foi a partir das realidades do campo brasileiro que surgiram as condições da emergência deste movimento na luta por direitos que estão na dimensão do público e do tratamento público destas questões. Tal processo é inspirado na efetivação do ideal democrático de cidadania e, por fim, articulado à crítica à educação até então hegemônica e à construção de uma educação da classe trabalhadora do campo.

Assim, a educação do campo poderia ser compreendida e contextualizada à luz desta tríade, por ser constituída a partir destes três elementos relacionados, que não estão livres de contradições. Estas possíveis contradições da luta por educação do campo, pensada a partir do campo, das políticas públicas e da educação, são algumas das problematizações candentes, principalmente no que se refere à dimensão pública da luta, ou seja, a luta por políticas públicas educacionais, materializadas na contradição entre Estado e Movimentos Sociais que, mesmo envolvendo riscos, apresenta inúmeras possibilidades de avanço e inovação.

Ao fazer suas ponderações sobre o surgimento do movimento por uma educação do campo, Vendramini (2007) contribui com uma importante reflexão sobre o momento histórico de organização do mesmo que, segun- 
do a autora, se configura de maneira mais concreta na I Conferência Nacional Por uma Educação Básica do Campo, em 1998. Este momento de efetivação de uma resistência camponesa já vinha se delineando a um bom tempo na luta de acampados e assentados por escolas no e do campo e por educação específica e de qualidade:

Uma importante e significativa mudança de teoria e de prática no que se refere à educação rural foi o movimento nacional desencadeado para a construção de uma escola do campo, vinculada ao processo de construção de um projeto popular para o Brasil, que inclui um novo projeto de desenvolvimento para o campo. Nesta orientação, foram realizadas diversas conferências estaduais e nacionais, sendo a primeira conferência nacional "Por uma Educação Básica do Campo”, realizada em 1998 e organizada pelo MST, CNBB, UNICEF e UNESCO. Essa primeira Conferência inaugurou uma nova referência para o debate e mobilização nacional: Educação do Campo e não mais educação rural ou educação para o meio rural, ao reafirmar a legitimidade da luta por políticas públicas específicas e por um projeto educativo próprio para os sujeitos que vivem e trabalham no campo. (Vendramini, 2007:123).

Nesse aspecto, é conveniente destacar que não seria a educação do campo uma educação segmentada ou segregada que teria por objetivo um ensino homogeneizador, não levando em consideração outras particularidades e diversidades que não as suas, até mesmo pela ampla diversidade cultural dos próprios povos do campo. Este movimento, ao valorizar as culturas campesinas, não negligenciaria todo o aporte teórico cientifico acumulado pela humanidade, o que nos faz admitir que, embora façamos neste trabalho críticas contundentes ao projeto de modernidade, é necessário reconhecer as contribuições que o conhecimento científico pode ensejar ao próprio movimento. A crítica se faz, portanto, ao caráter excludente da educação e do pensamento moderno colonial. Deste modo, um projeto de educação do campo exigiria

Uma educação que garanta o direito ao conhecimento, à ciência e à tecnologia socialmente produzidas e acumuladas. Mas também que contribua na construção e afirmação de valores e da cultura, das auto-imagens e identidades da diversidade que compõem hoje o povo brasileiro do campo (Arroyo, Caldart, Molina, 2004: 14).

A despeito do reconhecimento da diversidade dos povos do campo, ao analisar alguns dos principais marcos legislacionais e de movimentos sociais nas lutas pela educação do campo, Taffarel (2012) considera a continuidade de confrontos entre projetos históricos de escolarização que continuam sendo determinados por conflitos e concepções que permeiam a luta no campo e materializam contradições que, por sua vez, distinguem tais projetos de educação. Nesse aspecto, esta autora alerta sobre o cuidado que devemos ter sobre os sentidos da diversidade que podem pulverizar os confrontos e conflitos nas lutas sociais do campo com repercussões nos 
processos formativos dos sujeitos do campo.

Destarte, acreditamos ser a educação rural um paradigma que norteou e possivelmente ainda nortearia as políticas públicas para a educação nas escolas rurais, oficializado e materializado na teoria e na prática, mesmo não sendo admitida política e ideologicamente. Entretanto, a emergência da educação do campo como um paradigma em construção fez força frente ao Estado brasileiro que, em tese, teria assumido tais reivindicações colocando-as na agenda oficial do governo, criando a Secretaria de Educação Continuada, Alfabetização, Diversidade e Inclusão (SECADI). É criado, também, um Grupo de Trabalho de Educação do Campo; a promulgação das Diretrizes Operacionais para a Educação Básica nas Escolas do Campo e as Diretrizes Complementares, Normas e Princípios para o Desenvolvimento de Políticas Públicas de atendimento da Educação Básica do Campo, o Decreto 7.352/ 10, que dispõe sobre a Política de Educação do Campo e o Programa Nacional de Educação na Reforma Agrária - PRONERA e, por fim, o Programa Nacional de Educação do Campo - PRONACAMPO, em 2012. Esse conjunto de ações e marcos legais, contribuem, segundo Caldart (2007:2) para que

(...) na medida em que a Educação do Campo vai se afirmando na sociedade, que entra como nome de secretarias ou coordenações de governos, que aparece como especificidade de preceitos legais, que dá nome a cursos e a linhas de pesquisa, que indica determinadas práticas ou reflexões de movimentos sociais, de movimentos sindicais ou de grupos sociais específicos, começa a aparecer uma tendência que desloca a Educação do Campo de sua identidade originária. A tendência é a de descolar estes termos dependendo dos interesses em questão ou dos sujeitos envolvidos no debate ou nas práticas e situações de conflito.

Neste contexto, podemos observar importantes avanços na construção de uma educação do campo, principalmente no que diz respeito aos marcos jurídicos. Contudo, a política de fechamento das escolas no Brasil rural impõe obstáculos à implementação das leis que preconizam a educação do campo. Outra questão importante é a possibilidade de cooptação, por parte do Estado dos princípios da Educação do Campo, originalmente construídos pelos povos do campo, princípios estes indissociáveis da luta pela reforma agrária. Interrogamos, portanto, até que ponto as políticas públicas apresentadas como políticas da educação do campo são políticas pautadas nas reivindicações e objetivos dos movimentos sociais rurais e até que ponto os governos estaduais e municipais seguem as diretrizes promulgadas pelo Estado em favor da Educação do Campo. Apreendemos que existem disputas pela hegemonia de sentidos (Alvarenga, 2010) sobre a educação do campo posto que é um conceito novo, mas já está em disputa, exatamente por que o movimento da realidade que ele busca expressar é marcado por contradições sociais muito fortes. (Caldart, ibid: 2).

Este questionamento em relação ao comprometimento do Estado brasileiro com a Educação do Campo se faz necessário por vários processos 
em curso. Os dois primeiros aspectos, já apresentados, fazem referência à precarização e à urbanocentralidade das escolas do campo, efetivados a partir da materialização da educação rural, o mais recente, porém, é o fechamento de escolas rurais. Estes processos estão amplamente relacionados com as políticas públicas implantadas atualmente nas escolas do campo ou que tenham como alvo alunos residentes em áreas rurais, o que faz a análise das mesmas um aspecto central nesta pesquisa e que, provavelmente, desvendará várias dimensões da precariedade e da urbanocentralidade, como igualmente poderá apontar outros processos de efetivação ou de superação da educação rural.

Para tanto, vemos a configuração de um embate paradigmático, representado pelo projeto de educação rural, fundamentado nos interesses da oligarquia rural e dos grupos urbano-industriais, o qual tem como parâmetros históricos a fixação do homem no campo, a manutenção da concentração fundiária e das relações desiguais no campo, e mais recentemente o esvaziamento do campo através da retração da oferta escolar rural, e pelo projeto de Educação do Campo, fundamentado nos interesses dos povos do campo organizados em movimentos sociais rurais, visando o desenvolvimento do campo brasileiro, por meio principalmente da reforma agrária, do estabelecimento de relações igualitárias no meio rural e da construção de uma educação específica.

\section{A política de nucleação das escolas do campo em dados}

A despeito do paradigma emergente da Educação do Campo, uma das políticas públicas postas em práticas é a nucleação das escolas do campo, política esta pautada na relação custo-benefício, vale dizer, em medidas de controle e ajuste financeiro/administrativo em detrimento do aspecto pedagógico. O caráter de tais medidas demonstra existir um explícito distanciamento entre as reivindicações da educação do campo, o discurso oficial do Estado e as políticas públicas educacionais implementadas. É sobre esta política que nos dedicaremos a problematizar a seguir.

Inicialmente ressaltamos que a análise das políticas públicas educacionais em curso no meio rural brasileiro indica uma duplicidade evidenciada pela manutenção de políticas antagônicas: por um lado políticas federais que visam a constituição de uma política nacional de educação do campo, atendendo parcialmente as reivindicações dos povos do campo e, por outro lado, políticas estaduais e municipais de nucleação de escolas rurais, que visam o fechamento de escolas rurais.

A política de nucleação de escolas, por nós analisada, refere-se à desativação de unidades escolares, principalmente as de pequeno porte situadas em áreas rurais, unidocentes (com um único professor) e/ou multisseriadas (com várias séries escolares em uma mesma sala de aula) ou até mesmo seriadas, algumas vezes denominadas de escolas isoladas, bem como a transferência dos alunos das escolas desativadas para escolas- 
núcleo, nas quais, supostamente, reuniria condições mais favoráveis, tanto no que diz respeito às condições físicas estruturais quanto nas de caráter didático-pedagógico.

No presente artigo, tomamos como referência municípios do estado do Rio de Janeiro e, conforme ilustra o gráfico abaixo, os dados apresentados corroboram para uma leitura sobre a ocorrência da política de fechamento de escolas rurais que vem sendo intensificada. Verificamos que, entre os anos de 2008 e 2010, 47\% dos municípios do estado do Rio de Janeiro retraíram a oferta escolar no campo, por meio do fechamento de escolas rurais. Em contrapartida, 13\% dos municípios expandiram esta oferta. Este processo ocorreu em todas as etapas da educação básica, sendo que no Ensino Médio a oferta escolar no campo mostra-se extremamente reduzida, visto que somente $39 \%$ dos municípios do estado ofereceram esta etapa no ano de 2010.

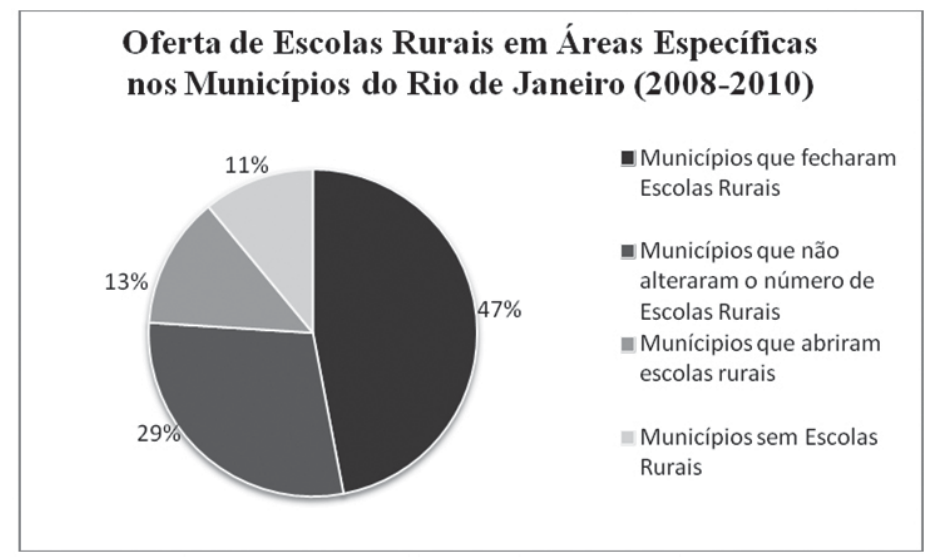

Fonte: Gráfico Organizado a partir de dados dos Indicadores Demográficos e Educacionais (MEC, 2011).

Destacamos que grande parte das escolas-núcleo, ou seja, escolas que receberam estudantes daquelas que foram desativadas, está presente em áreas urbanas. Assim, faz-se necessária a prática de deslocamento dos estudantes de suas comunidades de origens para os centros urbanos, muitas vezes para escolas extremamente distantes e por meio de transporte precário. O pretexto para tal política é, em si, uma violência, já que as escolas rurais recebem o estigma de "escolinhas” com precárias condições infraestruturais de ensino e a melhor solução, para muitos governos subnacionais, seria fechar as escolas rurais, como se as mesmas fossem sinônimos de má qualidade e fracasso educacional.

Devemos deixar claro que o fechamento de escolas rurais não é mera 
especulação ou suposição, segundo a Campanha Fechar escola é crime ${ }^{5}$ (2011), do Movimento dos Trabalhadores Rurais Sem Terra (MST), nos últimos oito anos mais de 24 mil escolas rurais foram fechadas no território brasileiro. (MST, 2011). De acordo com dados do Censo Escolar publicados por Rodrigues e Lins (2011), nos últimos dez anos 37.776 estabelecimentos de ensino rurais foram fechados no país, o que seria resultado dos processos de nucleação escolar e de concentração fundiária, questões que mereceriam ser mais discutidas e mencionadas devido aos seus impactos sociais.

No manifesto lançado na campanha Fechar Escola é Crime, os signatários fazem uma breve contextualização e avaliação da prática de fechamento de escolas do campo no Brasil, demonstrando a preocupação dos atores envolvidos na luta por educação do campo com o processo de nucleação escolar e a necessidade de aprofundamento do debate com a sociedade civil em geral.

Para essas famílias camponesas, o anúncio do fechamento de uma escola na sua comunidade ou nas redondezas significa relegar seus filhos ao transporte escolar precarizado, às longas viagens diárias de ida e volta, saindo de madrugada e chegando ao meio da tarde; à perda da convivência familiar, ao abandono da cultura do trabalho do campo e a tantos outros problemas. [...] Portanto, fechar uma escola do campo significa privar milhares de jovens de seu direito à escolarização, à formação como cidadãos e ao ensino que contemple e se dê em sua realidade e como parte de sua cultura. Num país de milhares de analfabetos, impedir por motivos econômicos ou administrativos o acesso dos jovens à escola é, sim, um crime! (MST, 2011).

Já os Indicadores Demográficos e Educacionais, registrados pelo Ministério da Educação (MEC), vemos que no estado do Rio de Janeiro, entre 2007 e 2010, o número de escolas municipais do campo que oferecem o ensino fundamental, etapa obrigatória da Educação Básica no Brasil, caiu de 1.154 para 1.084. Ou seja, houve o fechamento de 70 escolas e/ou a desativação desta etapa de ensino em escolas rurais em um espaço de tempo relativamente curto.

Enquanto isso, o número de escolas urbanas municipais que ofertam a mesma etapa de ensino subiu de 2.631 para 2.673, um acréscimo de 42 escolas no mesmo período. O mesmo veio a ocorrer com a rede estadual de educação. Porém, a questão das municipalizações deve ser levada em consideração, já que muitas escolas estaduais de ensino fundamental, tanto urbanas quanto rurais, foram transferidas para a responsabilidade das prefeituras. (MEC/INEP, 2011).

No que tange à desigualdade educacional no Brasil, Patto (2000) considera que a produção do fracasso escolar estruturou-se a partir de três modalidades de exclusão: a primeira diz respeito à impossibilidade de acesso; a segunda forma de produção do fracasso escolar é designada pela autora 


\section{como exclusão precoce e, a terceira, inclusão sem usufruto.}

Sobre a impossibilidade de acesso, reconhecemos que, embora tenhamos avançado na universalização da Educação Fundamental, o mesmo não pode ser dito sobre a educação infantil e o ensino médio. Sobre a exclusão precoce dos alunos, sabemos que muitos desistem de seus percursos escolares por razões intra e/ou extra/escolar, efeitos de múltiplas desigualdades. Já sobre a inclusão sem usufruto, o que consideramos uma inclusão precária, pois o acesso à escola não significa o usufruto da escola de qualidade pedagógica, material e social paras as crianças, jovens e adultos das classes populares. Essas três modalidades ainda persistem e acreditamos que a política por nós discutida, de nucleação escolar, pode ser um fator de intensificação desta exclusão, já que a distância entre residência e escola se não impossibilita, ao menos dificulta o acesso à mesma.

Esta dificuldade que poderá acarretar em faltas excessivas e cansaço durante as aulas e direcionar-se para a ampliação das probabilidades de exclusão precoce, seja por evasão, seja por repetência acentuada, bem como o processo de ensino-aprendizagem a partir de outros olhares, territórios e necessidades, poderá igualmente contribuir para uma inclusão sem usufruto, na medida em que a educação pode estar descolada das realidades e necessidades mais básicas das populações do campo.

Segundo Bof, Sampaio e Oliveira (2006:196), na sua maioria, os municípios por eles pesquisados possuem escolas rurais que não adotam nenhuma estratégia específica de educação para o meio rural. Em relação às escolas pesquisadas a maioria (63\%) não possui uma estratégia especifica ao meio rural; 14,3\% são nucleadas, $10 \%$ Escolas Ativas, $4 \%$ são escolas de assentamento e menos de $0,5 \%$ são centros de pedagogia da alternância (ibid: 198), sendo que a maior parte das escolas nucleadas encontra-se na região Centro-Sul. De acordo com a mesma pesquisa, nos municípios analisados existem 391 escolas polo ou escolas-núcleo. Acreditamos, todavia, que em nível nacional os números de escolas-núcleo devam ser bem maiores do que os dados oficiais, pois pode ser de praxe o fechamento de escolas rurais de pequeno porte e, consequentemente, a transferência dos alunos para escolas rurais ou urbanas de médio ou grande porte, sem que as mesmas sejam consideradas oficialmente escolasnúcleo.

Vendramini (2007:122), ao refletir sobre a educação e trabalho no campo, pensa a questão de como a nucleação escolar permanece presente na estrutura educacional brasileira, de acordo com a mesma orientada a partir do primeiro Plano Nacional de Educação (Projeto de Lei 4.173/98), documento que norteou as políticas públicas nacionais entre 2001 e 2010:

No que se refere ao contexto educacional, observamos a continuidade da política de fechamento/nucleação de escolas rurais, com o objetivo de racionalizar a estrutura e a organização de pequenas escolas, em comunidades que contam com um reduzido número de classes 
multisseriadas, orientando-se pelo Plano Nacional de Educação (Projeto de Lei $n^{\circ}$. 4.173/98).

Em sua pesquisa referente às políticas públicas educacionais para as escolas do Brasil rural Bof, Sampaio e Oliveira concluem que:

Os resultados deste estudo indicam que a maior parte dos municípios brasileiros não desenvolve ações específicas em relação à provisão educacional nas zonas rurais. A maioria dos que o fazem parece estar seguindo a estratégia da nucleação, que consiste na desativação de escolas rurais menores e na criação de escolas-pólo, com [...] o transporte das crianças que residem nas áreas rurais para escolas existentes no núcleo urbano. (Bof, Sampaio, Oliveira, 2006: 206).

Entende-se que, além da maioria dos municípios não desenvolver políticas específicas para as escolas do campo, os governos que as desenvolvem optam pela nucleação, ancorados em uma ideia de racionalização do gerenciamento das políticas educacionais. Ao refletir sobre esta questão Arroyo faz as seguintes considerações:

A solução me parece que não é tirar as crianças de seu lugar e leválas para outro lugar. A famosa nucleação de escolas. (...) Porque a escola tem que estar vinculada às raízes de suas vivências, de sua família, de sua experiência completa. A escola tem que estar colada às raízes mais imediatas das vivências de infância. Não podemos fazer da escola uma espécie de supermercado. A questão é que a educação fundamental se estiver colada ao cotidiano da vivência das crianças, tem que estar no lugar onde a criança vive, se produz e reproduz. Criar escolas-núcleo, distantes dos espaços de vivência da criança, desarraiga, tira da raiz. (Arroyo apud Kremer, 2010: 4).

Embora seja a política mais posta em prática nas escolas rurais, para muitos pesquisadores e para o movimento que luta por uma educação do campo, a nucleação não seria a melhor solução para a educação no meio rural e não estaria ocorrendo a partir de um diálogo com as comunidades rurais e escolares afetadas, o que nos faz considerar que, principalmente nestas condições, não deveria ser uma política pública educacional privilegiada, como já anunciado pela campanha e pelo manifesto contra o fechamento de escolas rurais.

\section{Notas para algumas conclusões}

Acreditamos que tanto o processo de luta pela materialização de uma Educação do Campo quanto o processo de fechamento de escolas rurais conformam, respectivamente, processos de espacialização e desterritorialização que promovem impactos socioespaciais relevantes, articulados aos impactos subjetivos, nos sujeitos do campo. Assim, a luta dos movimentos sociais rurais pela consolidação da educação do campo 
conformaria em tese um processo, inacabado, de espacialização deste movimento nas escolas e nos espaços rurais brasileiros.

Apesar da disputa entre Estado (historicamente impondo a educação rural) e Movimentos Sociais (construindo a educação do campo), podemos considerar que a maior parte das escolas rurais brasileiras está sob a gestão estatal para realizar suas funções, não necessariamente vinculadas aos sentidos produzidos pelos movimentos sociais que têm historicamente mobilizado lutas pelo direito à terra e pelo direito à educação, apesar das consideráveis conquistas, o que faz da educação do campo um processo em construção, por isso inacabado.

A duplicidade nas políticas públicas de educação do campo constitui uma grave contradição e ameaça à materialização de uma política nacional de educação do campo, que atenda aos objetivos dos povos do campo em âmbito nacional. As medidas impostas pelo Estado brasileiro até o momento não foram capazes de frear o avanço da política de nucleação de escolas rurais nos estados e municípios do país. Neste contexto, foi sancionada recentemente a Lei 12.960/14 que dificulta o fechamento de escolas rurais, indígenas e quilombolas, por meio da exigência de parecer de órgão normativo e opinião da comunidade escolar possivelmente afetada, com o intuito de que existam justificativas reais para o encerramento das atividades da escola (MST, 2014).

Nesta perspectiva, a disputa paradigmática entre educação rural e educação do campo ganha novas dimensões, pois se delineia uma disputa dentro do próprio Estado brasileiro que envolve por um lado a afirmação da educação do campo, na construção de uma política nacional de educação do campo, e, por outro lado, a ressignificação do projeto de educação rural, por meio da política de nucleação de escolas rurais.

Por fim, consideramos que a emergência da luta por uma educação do campo, pautada nas necessidades dos movimentos sociais populares rurais, apesar de vir conquistando vitórias no que diz respeito à educação dos povos do campo, vem sofrendo um grande golpe com o processo de fechamento de escolas rurais e nucleação escolar que dificulta a materialização de uma educação do campo no espaço rural brasileiro. Neste contexto, a escola rural é um território em disputa. Daí a necessidade de pesquisas que deem continuidade e visibilidade na produção de conhecimentos sobre os impactos e repercussões sobre as políticas para a educação dos sujeitos em espaços não-urbanos no Brasil e em países de contextos políticos, sociais e econômicos similares. 


\section{Notas}

${ }^{1}$ Este artigo é parte de um dos resultados de pesquisa concluída no ano de 2013, no Programa de Pós-Graduação Mestrado em Educação - Processos Formativos e Desigualdades Sociais - Rio de Janeiro/Brasil

${ }^{2}$ Sobre a problemática que envolve o império da tese liberal elitista sobre a inferioridade dos povos do campo ver Paiva (1973) e Alvarenga (2009).

${ }^{3}$ Secretaria de Educação Continuada, Alfabetização e Diversidade. Atualmente Secretaria de Educação Continuada, Alfabetização, Diversidade e Inclusão (SECADI).

${ }^{4}$ Invasão cultural é a penetração que fazem os invasores no contexto cultural dos invadidos, impondo a estes sua visão do mundo, enquanto lhes freiam a criatividade, ao inibirem sua expansão. (Freire, 2005: 173).

${ }^{5}$ Campanha número 46 "Fechar Escola é crime”. Movimento dos Trabalhadores Rurais Sem Terra, 2011. 


\section{Bibliografia}

Alvarenga, M. S. (2010), Sentidos da cidadania: políticas de educação de jovens e adultos. EdUERJ, Rio de Janeiro.

Alvarenga, M.S. (2009), "Da cegueira à orfandade: a questão da cidadania nas políticas de alfabetização de jovens e adultos (1947-2002)”. In. HISTEDBR on line. n. 36, p. 200-2015, Campinas.

Arroyo, M. A. (1982), Escola, cidadania e participação no campo. Em Aberto, INEP, v. 1 n 9, p. 1-6, set, Brasília.

Arroyo, M. G; Caldart, R. S. \& Molina, M. C. (orgs). (2004), Por uma Educação do Campo. Vozes, Petrópolis, RJ.

Bof, A. M; Sampaio, C. E. M; Oliveira, L. L. N. (2006), "Iniciativas de educação para o meio rural nos municípios brasileiro”. In: Bof, A. M. (org.) A Educação no Brasil Rural. Inep, Brasília.

Caldart, R. S. (2009), "Educação do campo: notas para uma análise de percurso”. Trab. Educ. Saúde, v. 7 n. 1, p. 35-64,mar./jun., Rio de Janeiro.

Ídem (2005), "Elementos para a construção de um projeto político e pedagógico da Educação do Campo". In: Molina, M. C; Jesus, S. M. A. Por uma educação do campo. Vol. 5. Articulação Nacional "Por Uma Educação do Campo", Brasília, DF.

Ídem (2007), Sobre educação do campo. II Seminário do Programa Nacional de Educação na Reforma Agrária (PRONERA), Luziânia (GO). Disponível em http://www.ce.ufes.br/educacaodocampo/down/cdrom1/pdf/ ii_03.pdf. Acesso em 11/10/11.

Freire, P. (2005), Pedagogia do oprimido. Paz e Terra, Rio de Janeiro.

Kremer, A. (2010), “A nucleação escolar e o processo de desenraizamento nas comunidades rurais do município de Bom Retiro/SC”. Anais do I Seminário de pesquisa em Educação do Campo. UFSC, Santa Catarina.

Leite, S. C. (2002), Escola Rural: urbanização e políticas educacionais. $2^{\mathrm{a}}$ Ed. Cortez, São Paulo.

MEC/ INEP. Indicadores demográficos e educacionais. Disponível em $<$ http://ide.mec.gov.br//2008/index.php>. Acesso em 11/10/2011.

MEC/INEP. Sinopse estatística da educação básica 2011. Disponível em: $<$ http://portal.inep.gov.br/basica-censo-escolar-sinopse-sinopse>. Acesso em $11 / 11 / 2012$. 
MEC/SECAD (2007), Cadernos SECAD 2 - Educação do Campo: Diferenças mudando paradigmas. SECAD, Brasília. DF.

Mendonça, S. (2012), “Estado e Ensino Rural no Brasil na Primeira Metade do Século XX: Balanço Historiográfico”. In. Estudios Rurales. Vol.1, n.3. p. 269-279, Quilmes.

Mendonça, S. R. (2007), Estado e educação rural no Brasil: alguns escritos. Vicio de Leitura/FAPERJ, Niterói/RJ.

MST. Educadores lançam manifesto contra o fechamento de escolas rurais. MST: 2011. Disponível em <http://www.mst.org.br/node/12562>. Acesso em 15/10/11.

MST. Sancionada lei que dificulta o fechamento de escolas do campo. MST: 2014. Disponível em <http://www.mst.org.br/node/15906> . Acesso em 14/ $01 / 2014$.

PARECER n 36/2001. Diretrizes operacionais para a educação básica nas escolas do campo. DF: CNE/CEB, 2001.

Paiva, V. (1973), Educação Popular e Educação de Adultos, Loyola, São Paulo.

Patto, M. H. S. (2000), “A miséria do mundo no Terceiro Mundo”. In: Mutações do Cativeiro: escritos de psicologia e política. Hacker Editores/ Edusp, São Paulo.

Pinto, J. M. R. et al. (2006), “O desafio da educação do campo”. In: BOF, A. M. (org.) A Educação no Brasil Rural. Inep, Brasília.

Rodrigues, K; Lins, L.(2011), Campo tem analfabetismo em 23\% e mais de 37 mil escolas fechadas. Jornal O Globo, 2011, Rio de Janeiro.

Taffarel, C.N.Z. (2012), "Políticas Públicas, educação do campo e formação de professores para a escola do campo”. In Alvarenga M.S. et al (2012). Educação Popular, Movimentos Sociais e Formação de professores: outras questões, outros diálogos. EdUERJ, Rio de Janeiro.

Vendramini, C. R. (2007), “Educação e trabalho: reflexões em torno dos movimentos sociais do campo”. In: Cadernos Cedes 72. Educação do Campo. Cortez; Campinas, São Paulo.

Recibido: 28.01.2014

Aceptado: 25.10.2014 